\title{
Birth outcomes in a Swedish population of women reporting a history of violence including domestic violence during pregnancy: a longitudinal cohort study
}

Hafrún Finnbogadóttir ${ }^{1 *}$, Kathleen Baird² and Li Thies-Lagergren ${ }^{3}$

\begin{abstract}
Background: Victimisation of women is encountered in all countries across the world, it damages the mental and physical health of women. During pregnancy and the postpartum period, women are at a greater risk of experiencing violence from an intimate partner. The aim of this study was to explore childbirth outcomes in a Swedish population of women reporting a history of violence including domestic violence during pregnancy.

Methods: A longitudinal cohort design was used. In total, 1939 pregnant women $\geq 18$ years were recruited to answer two questionnaires, both questionnaires were administered in the early and late stages of their pregnancy. The available dataset included birth records of 1694 mothers who gave birth between June 2012 and April 2014. Statistical analyses included descriptive statistics, T-test and bivariate logistic regression.

Results: Of 1694 mothers 38.7\% $(n=656)$ reported a history of violence and 2\% $(n=34)$ also experienced domestic violence during pregnancy. Women who were single, living apart from their partner, unemployed, smoked and faced financial distress were at a higher risk of experiencing violence $(p=0.001)$. They also had significant low scores on the SOC-scale and high EDS-scores $\geq 13$ ( $p=0.001)$ when compared to women without a history of violence $(p=0.001)$. Having a history of violence increased the woman's risk of undergoing a caesarean section (OR $1.33,95 \% \mathrm{Cl} 1.02-1.70$ ). A history of emotional abuse also significantly increased the risk of having a caesarean section irrespective of whether it was a planned or an emergency caesarean section (OR 1.50,95\% Cl 1.09-2.06). Infants born to a mother who reported a history of violence, were at significant risk of being born premature $<37$ weeks of gestation compared to infants born by mothers with no history of violence $(p=0,049)$.

Conclusions: A history of violence and/or exclusively a history of emotional abuse has a negative impact on childbirth outcomes including caesarean section and premature birth. Therefore, early identification of a history of or ongoing violence is crucial to provide women with extra support which may have positive impact on her birth outcomes.
\end{abstract}

Keywords: History of violence, Domestic violence, Intimate partner violence, Pregnancy, Midwife, birth outcomes, Longitudinal, Cohort-study

\footnotetext{
* Correspondence: hafrun.finnbogadottir@mau.se

${ }^{1}$ Faculty of Health and Society, Department of Care Science, Malmö University, Malmö, Sweden

Full list of author information is available at the end of the article
}

(c) The Author(s). 2020 Open Access This article is licensed under a Creative Commons Attribution 4.0 International License, which permits use, sharing, adaptation, distribution and reproduction in any medium or format, as long as you give appropriate credit to the original author(s) and the source, provide a link to the Creative Commons licence, and indicate if changes were made. The images or other third party material in this article are included in the article's Creative Commons licence, unless indicated otherwise in a credit line to the material. If material is not included in the article's Creative Commons licence and your intended use is not permitted by statutory regulation or exceeds the permitted use, you will need to obtain permission directly from the copyright holder. To view a copy of this licence, visit http://creativecommons.org/licenses/by/4.0/ The Creative Commons Public Domain Dedication waiver (http://creativecommons.org/publicdomain/zero/1.0/) applies to the data made available in this article, unless otherwise stated in a credit line to the data. 


\section{Background}

Violence against women (VAW) continues to be one of the biggest violations against human rights with every third woman worldwide being exposed to physical and/ or sexual violence [1]. Women living in Sweden are no exception to such statistics [2, 3]. Pregnancy is not a safeguard or protector against intimate partner (IPV) or family violence [4-6].

In this study, the terms 'history of violence', Domestic Violence (DV), Intimate Partner Violence (IPV) and the concept of 'domestic and family violence' (DFV), will be used interchangeable to describe DV. "A history of violence is defined as a lifetime experience of emotional, physical or sexual abuse occurring during childhood ( $<18$ years), adulthood $(\geq 18$ years) or both, regardless of the level of abuse or the perpetrator's identity" [3]. The definition of DV used in the study is in agreement with the World Health Organization (WHO) description [7]. DV commonly takes place in the woman's 'own home' [8].

Home is often considered as a place of safety, a haven for women and children, a place where there is physical and psychological safety, trust and care [9]. However, for many women, what should be a place of safety, becomes an environment which is characterised by threat, fear and victimisation for many women experiencing DV [10]. Over the past two decades, research has highlighted the multidimensional effects of DV [11]. Women who experience DV have more medical and stress related symptoms, higher risk of substance misuse than nonabused women. It is also known that women living with violence are higher users of health care services with an estimated 30-50\% higher use rate of Emergency Department [12]. Despite this, the response from healthcare in relation to DV is often inadequate and DV remains undetected also for pregnant women [13].

According to WHO, globally 1 to $28 \%$ of women are physically abused during pregnancy by an intimate partner [14]. In Australia, 36\% of women who experienced violence by a partner reported that this occurred when they were pregnant and around $17 \%$ of these women experienced, violence for the very first time during pregnancy [15]. A meta-analysis by James and colleagues exposed an overall prevalence rate of $13.3 \%$ of DV during pregnancy in high-income countries [16]. In Europe, $20 \%$ of pregnant women experienced IPV from a current partner with $42 \%$ of the women reporting IPV from a previous partner [17]. Whereas in Sweden, recent results from a longitudinal cohort study completed in southwest Sweden revealed a DV prevalence rate of $2.5 \%$ of the pregnant population $[18,19]$.

A growing body of evidence exploring the effects of IPV during pregnancy confirms that it leads to an increase in behavioural risk factors associated with adverse birth outcomes, such as maternal smoking, alcohol or drug misuse, inadequate prenatal care, or insufficient prenatal weight gain $[20,21]$. Women who are subjected to IPV are predisposed to have higher levels of stressrelated hormones which can be accelerated through physical and sexual trauma leading to preterm birth and low birth weight [22] resulting in reducing mother's and child's immune system [21]. A history of sexual violence may lead to fear of childbirth $[23,24]$ increasing the risk of both planned and emergency caesarean section (CS) [24].

In addition, being exposed to violence and abuse during pregnancy facilitates direct and indirect path-ways to adverse birth outcomes [20]. For example, placental damage, uterine contractions, premature rupture of membranes, and genitourinary infections are among some of the pregnancy complications and adverse outcomes caused by direct physical assault and sexual assault [21]. Women exposed to DV during pregnancy and the postpartum period are also at a greater risk of lifelong health consequences [22]. The condition of the mother's health and wellbeing is also reflected in the health and wellbeing of the foetus and the new-born infant [25]. Consequences of abuse for maternal, foetal, and child health outcome is poorer physical and psychological health during pregnancy [26-28]. International literature has also revealed that women who are exposed to DV have a significantly increased risk for depression during both prenatal and postpartum period [28].

Currently, in Sweden, there continues to be limited knowledge relating to birth outcomes in women who have been subjected to DV before and/or during pregnancy. Consequently, the overall aim of this study is to explore childbirth outcomes in a Swedish population of women reporting a history of violence including domestic violence during pregnancy.

\section{Methods}

The study used a longitudinal design and is part of a previous published project 'Pregnant women and new mothers' health and life experience, with 'life experience' which also included collecting data around intimate partner violence $[3,18,19]$. Included participants were primigravida and multiparous women $\geq 18$ years of age, receiving antenatal care (ANC), and who could read and write in Swedish or English.

\section{Participants}

Recruitment to the study was performed prospectively between March 2012 and September 2013 area in the southwest of Sweden, which is multiethnic. The study population includes all pregnant women at total 17 ANCs situated in the multiethnic city, a University City and in smaller municipalities. In the present study, more 


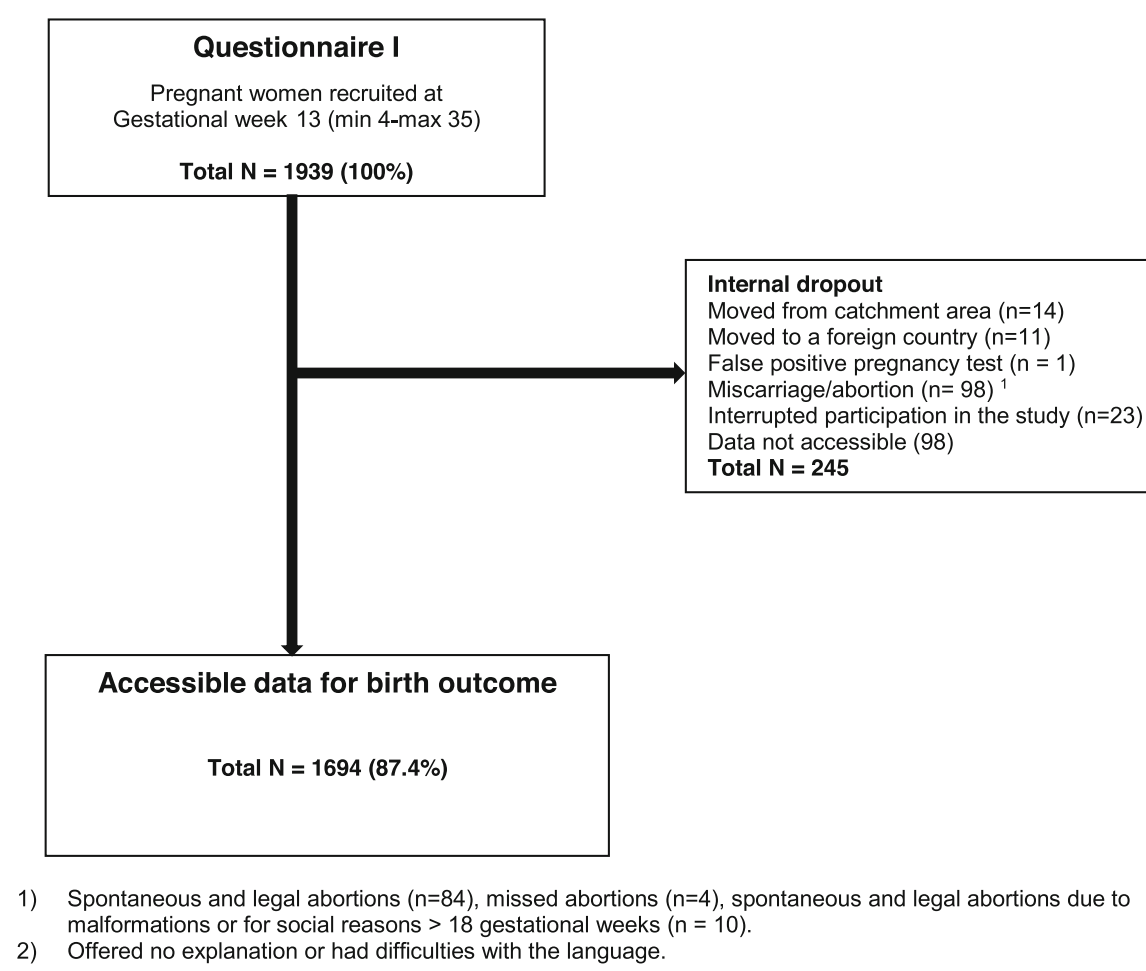

Fig. 1 Flowchart over distributed and received answers from Questionnaires I-II and birth files

than $50 \%$ of the women lived in the multicultural city were almost a third of the inhabitants are born abroad and come from 186 different countries. Overall, the participants in the present study represented 93 different countries. Altogether, 1939 pregnant women were recruited to the study. Recruitment usually occurred early in the second trimester (mean, 12.8, SD 5.11) [3] by midwives working in maternal health care. Further details regarding the recruitment process and the study setting are described in detail in another paper [3].

\section{Data collection}

The available dataset included in the study involved the health records of 1694 mothers who gave birth between June 2012 and April 2014 (Fig. 1).

\section{Survey and tools}

Questionnaires (QI and QII) were administered and completed early in the second trimester and again in late pregnancy, usually around gestational week 34 (mean 33.9; SD 2.20) information was also extracted from the birth register regarding the women's birth outcomes.

Questionnaires included (Q-I - Q-II) the NorVold Abuse Questionnaire (NorAQ) which has been used previously for collecting similar data demonstrating its validity and reliability [29]. Other questionnaires included Edinburgh Postnatal Depression Scale (EPDS) [30], which is common tool used during pregnancy (EDS) and following childbirth to access a woman's risk of developing postnatal depression [31]. The EPDS has a 72\% sensitivity and $88 \%$ specificity for women in the postpartum period but has a lower degree of detection for depression during pregnancy [32]. The cut-off score for depression is usually set at 12/13 [30] the cut off chosen for this study was 13 . The sense of coherence (SOC) scale measured the women's' stress management and their use of own resources to maintain and improve health. The instrument is reliable, valid and cross-culturally appropriate with acceptable face validity and consists of 13 items [33]. A high SOC score is a predictor of good health and is strongly related to perceived health, especially mental health [34]. The Alcohol Use Disorders Identification Test (AUDIT) [35] was also used at each time of questionnaire administration (Q-I - Q-II). For this study, the women were only asked the first question; How often do you have a drink containing alcohol? In Sweden, the AUDIT questionnaire is routinely used in antenatal care to collect information about the woman's alcohol intake during pregnancy.

\section{Classification of the variables}

For sociodemographic factors as well as maternal characteristics similar or same classifications were used as in previous publications, but the material has same origin $[3,18,19]$. Age was classified as $18-25,26-34$ and $\geq 35$ years. Cohabiting status was classified as single/living 
Table 1 Socio-demographic factors at recruitment in early second trimester $(N=1694)$

\begin{tabular}{|c|c|c|c|c|}
\hline \multirow{3}{*}{$\begin{array}{l}\text { Characteristics } \\
\text { Total n (\%) }\end{array}$} & \multirow[t]{2}{*}{ Total } & \multicolumn{2}{|c|}{ History of violence $^{1}$} & \multirow[t]{3}{*}{$P$} \\
\hline & & No & Yes & \\
\hline & $\begin{array}{c}n(\%) \\
1687(100)\end{array}$ & $\begin{array}{c}n(\%) \\
1031(61.1)\end{array}$ & $\begin{array}{c}n(\%) \\
656(38.9)\end{array}$ & \\
\hline Age, years & & & & 0.426 \\
\hline $18-25$ & $293(17.6)$ & $178(17.4)$ & $115(17.9)$ & \\
\hline $26-34$ & $1067(64.1)$ & $666(65.2)$ & $401(62.4)$ & \\
\hline$\geq 35$ & $305(18.3)$ & $178(17.4)$ & $127(19.8)$ & \\
\hline \multicolumn{5}{|l|}{ Missing $=29$} \\
\hline Cohabiting status & & & & 0.001 \\
\hline Single/Living apart & $84(5.1)$ & $30(3.0)$ & $54(8.5)$ & \\
\hline Common law spouse/married & $1554(94.9)$ & $969(97.0)$ & $585(91.5)$ & \\
\hline \multicolumn{5}{|l|}{ Missing $=56$} \\
\hline Language & & & & 0.229 \\
\hline Swedish & $1271(75.5)$ & $766(74.5)$ & $505(77.1)$ & \\
\hline Foreign language & $412(24.5)$ & $262(25.5)$ & $150(22.9)$ & \\
\hline \multicolumn{5}{|l|}{ Missing $=11$} \\
\hline Educational status & & & & 0.107 \\
\hline Low educational status & $555(32.9)$ & $324(31.4)$ & $231(35.2)$ & \\
\hline High educational status & $1132(67.1)$ & $707(68.6)$ & $425(64.8)$ & \\
\hline \multicolumn{5}{|l|}{ Missing $=7$} \\
\hline Employment status & & & & 0.001 \\
\hline $\begin{array}{l}\text { Employed } \\
\text { Unemployed }\end{array}$ & $\begin{array}{c}1595(94.6) \\
91(5.4)\end{array}$ & $\begin{array}{c}994(96.5) \\
36(3.5)\end{array}$ & $\begin{array}{c}601(91.6) \\
55(8.4)\end{array}$ & \\
\hline \multicolumn{5}{|l|}{ Missing $=8$} \\
\hline Financial distress & & & & 0.001 \\
\hline No & $886(52.6)$ & $584(56.7)$ & $302(41.6)$ & \\
\hline Yes & $799(47.4)$ & $446(43.3)$ & $353(53.9)$ & \\
\hline Missing $=9$ & & & & \\
\hline
\end{tabular}

Pre-specified level of statistical significance $<0.05$, two-tailed

${ }^{1}$ Reported experience of emotional, physical or sexual abuse during pregnancy irrespective severity

apart, or common law spouse/married. Language was dichotomised as Swedish language or foreign language spoken at home (including English). Educational status was classified as compulsory school or less to low educational status and, high school or less, or university to high educational status. Employment status was dichotomised as employed (including parental leave and studying) or unemployed (including long illness). Financial distress was dichotomised as "no" (no problem) or "yes" (serious financial distress). The question about financial distress was as follows; If you received unexpected bill of 20.000 SEK, how easy would it be for you to pay within a week? Responses included; no problem, fairly hard and very hard, which is expressed as 'serious financial distress'.

Maternal characteristics included Parity which was classified as primiparous versus multiparous. Body mass index (BMI) were calculated from maternal weight and height before the pregnancy and classified according to WHO's definition as underweight $(<18.5)$ / normal weight (18.50-24.99) versus overweight $(\geq 25-29.99)$ / obese $(\geq 30)$. Smoking/using wet tobacco was dichotomised into "yes" (if the woman was a daily smoker/ snuffer or smoking/snuffed at some point during pregnancy) and "no" (never smoked/wet-tobacco or ceased before pregnancy). Use of alcohol was dichotomised into "yes" (at least once a month or more) or "no". Fear of Birth yes or no.

For birth and labour outcome Labour initiation was dichotomized into spontaneous or induction (regardless of diagnosis or how the induction was initiated). Augmentation of labour was dichotomized into yes (with synthetic oxytocin) or no. The use of Epidural anaesthesia was dichotomized into yes or no. Birth mode were 
Table 2 Descriptive overview of maternal characteristics, in early second trimester of the pregnancy $(N=1694)$

\begin{tabular}{|c|c|c|c|c|}
\hline \multirow{4}{*}{$\begin{array}{l}\text { Characteristics } \\
\text { Total n (\%) }\end{array}$} & \multirow[t]{2}{*}{ Total } & \multicolumn{2}{|c|}{ History of violence ${ }^{1}$} & \multirow[t]{4}{*}{$P$} \\
\hline & & No & Yes & \\
\hline & n (\%) & n (\%) & n (\%) & \\
\hline & $1687(100)$ & $1031(61.1)$ & $656(38.9)$ & \\
\hline Parity & & & & 0.283 \\
\hline Primiparae & $708(45.2)$ & $419(44.2)$ & $289(46.9)$ & \\
\hline Multiparae & $857(54.8)$ & $530(55.8)$ & $327(53.1)$ & \\
\hline \multicolumn{5}{|l|}{ Missing $=129$} \\
\hline BMI & & & & 0.411 \\
\hline Underweight/ Normal weight & 1199 (73.8) & $742(74.5)$ & $457(72.7)$ & \\
\hline Overweight/ Obese & $426(26.2)$ & $254(25.5)$ & $172(27.3)$ & \\
\hline \multicolumn{5}{|l|}{ Missing $=69$} \\
\hline Smoking/Wet-tobacco & & & & 0.001 \\
\hline No & $1338(81.6)$ & $860(85.9)$ & $478(74.8)$ & \\
\hline Yes & $302(18.4)$ & $141(14.1)$ & $161(25.2)$ & \\
\hline \multicolumn{5}{|l|}{ Missing $=54$} \\
\hline Use of Alcohol & & & & 0.542 \\
\hline No & $773(47.4)$ & $467(46.8)$ & $306(48.3)$ & \\
\hline $\mathrm{Yes}^{2}$ & $858(52.6)$ & $531(53.2)$ & $327(51.7)$ & \\
\hline \multicolumn{5}{|l|}{ Missing $=63$} \\
\hline Fear of birth & & & & 0.159 \\
\hline No & $1625(96.4)$ & $998(96.9)$ & $627(95.6)$ & \\
\hline Yes & $61(3.6)$ & $32(3.1)$ & $29(4.4)$ & \\
\hline \multicolumn{5}{|l|}{ Missing $=8$} \\
\hline SOC & & & & 0.001 \\
\hline High score & $1194(74.7)$ & $782(81.4)$ & 412 (64.6) & \\
\hline Low score & 405 (25.3) & 179 (18.6) & $226(35.4)$ & \\
\hline \multicolumn{5}{|l|}{ Missing $=95$} \\
\hline EDS & & & & 0.001 \\
\hline Score $<13$ & $1492(90.9)$ & 934 (93.9) & $558(86.4)$ & \\
\hline Score $\geq 13$ & $149(9.1)$ & $61(6.1)$ & 88 (13.6) & \\
\hline Missing $=53$ & & & & \\
\hline
\end{tabular}

Pre-specified level of statistical significance $<0.05$, two-tailed

${ }^{1}$ Reported experience of emotional, physical or sexual abuse during pregnancy irrespective severity

${ }^{2} \mathrm{At}$ least once in a month

classified as vaginal birth (inclusive vacuum extraction and forceps) or caesarean section (inclusive planned and emergency section). Postpartum haemorrhage (PPH) was classified as bleeding $<1000 \mathrm{ml}$ or $\geq 1000 \mathrm{ml}$.

For infant characteristics and birth outcome gestational week was classified as premature $<37$ and as full term from $\geq 37$ weeks of gestation. Infant biological sex was dichotomized into female or male. Apgar scores at 5 min classified as $<7$ or $\geq 7$. Infant weight was distributed between <2500 g, 2500-4000 g and > $4000 \mathrm{~g}$. Transferred to Neonatal Intensive Care Unit (NICU), was dichotomized into yes or no.

\section{Data analysis}

Descriptive statistics were utilized to show prevalence. The $t$-test was used to compute mean age. Chi-square analysis was used to investigate differences in variables presenting sociodemographic, maternal characteristics, birth and labor outcome as well as infant characteristics in relation to 'history of violence'. OR and $95 \% \mathrm{CI}$ were calculated for the crude associations between possible risk factors and 'history of violence', with 'birth outcome' as a dependent variable for bivariate logistic regression. In order to analyze the association between the SOC score and exposure to 'history of violence', the SOC- 
Table 3 Maternal labour and birth outcome $(N=1694)$

\begin{tabular}{|c|c|c|c|c|}
\hline \multirow{3}{*}{$\begin{array}{l}\text { Characteristics } \\
\text { Total n (\%) }\end{array}$} & \multirow[t]{2}{*}{ Total } & \multicolumn{2}{|c|}{ History of violence $^{1}$} & \multirow[t]{3}{*}{$P$} \\
\hline & & No & Yes & \\
\hline & $\begin{array}{c}n(\%) \\
1687(100)\end{array}$ & $\begin{array}{c}n(\%) \\
1031(61.1)\end{array}$ & $\begin{array}{c}n(\%) \\
656(38.9)\end{array}$ & \\
\hline Labour initiation & & & & 0.136 \\
\hline Spontaneous & $1384(85.1)$ & $856(86.1)$ & $528(83.4)$ & \\
\hline Induction & $243(14.9)$ & $138(13.9)$ & $105(16.6)$ & \\
\hline \multicolumn{5}{|l|}{ Missing $=67$} \\
\hline Augmentation & & & & 0.946 \\
\hline No & $1058(68.5)$ & $649(68.5)$ & 409 (68.6) & \\
\hline Yes & $486(31.5)$ & $299(31.5)$ & $187(31.4)$ & \\
\hline \multicolumn{5}{|l|}{ Missing $=150$} \\
\hline Epidural anesthesia & & & & 0.067 \\
\hline No & $1267(78.5)$ & $788(80.0)$ & $479(76.2)$ & \\
\hline Yes & $347(21.5)$ & $197(20.0)$ & $150(23.8)$ & \\
\hline \multicolumn{5}{|l|}{ Missing $=80$} \\
\hline Labour outcome & & & & 0.036 \\
\hline Vaginal birth ${ }^{2}$ & $1430(84.8)$ & $889(86.2)$ & $541(82.5)$ & \\
\hline Caesarean section & $257(15.2)$ & $142(13.8)$ & $115(17.5)$ & \\
\hline \multicolumn{5}{|l|}{ Missing = 7} \\
\hline Post partum hemorrhage & & & & 0.259 \\
\hline$<1000 \mathrm{ml}$ & $1602(95.0)$ & $984(95.4)$ & $618(94.2)$ & \\
\hline$\geq 1000 \mathrm{ml}$ & $85(5.0)$ & $47(4.6)$ & $38(5.8)$ & \\
\hline Missing = 7 & & & & \\
\hline
\end{tabular}

Pre-specified level of statistical significance $<0.05$, two-tailed

${ }^{1} \mathrm{H}$ as reported experience of emotional, physical or sexual abuse during pregnancy irrespective severity

${ }^{2}$ Inclusive vacuum extraction $(n=121)$ and forceps $(n=10)$

scale was dichotomized utilizing the first quartile of the distribution as a cut-off value $(\mathrm{SOC} \leq 64$ and $\mathrm{SOC}>64$ ) [36]. The SOC score was only subtracted for those responding to all thirteen items (missing $=95$ ). To analyze the association between symptoms of depression during pregnancy an optimal cut-off of $\geq 13$ was chosen as representing the presence of symptoms of depression [31]. The EDS score was calculated solely for those replying to all ten questions (missing $=53$ ). Statistical significance was considered at $p<0.05$ (two-tailed). Statistical analyses were performed using the Statistical Package for Social Sciences (SPSS) version 25.0 for Windows.

\section{Results}

Accessible data to investigate for birth outcomes comprised of $87.4 \%(n=1694)$ of the original cohort $(N=$ 1939). The mean age (at recruitment) was 30 years (mean 30.12, SD 4.8; min 18-48 years) and for the majority of women Swedish was their first language. Among those women, almost 4 in 10 women reported a history of violence $(n=656)$, categories of significant difference were single or living apart, unemployed and experiencing financial distress (Table 1). In this particular cohort $2 \%(n=34)$ women reported experiencing DV during pregnancy (Q-I - Q-II) and all had a history of experiencing violence.

In the self-reported maternal characteristics and lifestyle questionnaire, more women were multipara, of normal weight or were underweight with less than $4 \%$ reporting fear of birth. Smoking or used wet-tobacco were significantly higher among women with a history of violence. Exposed women also reported a significant lower SOC score and higher EDS scores than women who did not report a history of violence (OR 2.40, 95\% CI (1.90-3.01) respectively (OR 2.41, 95\% CI 1.71-3.40). Alcohol consumption were similar in the two groups, regardless of whether they reported a history of violence or not (Table 2).

Maternal birth outcomes were similar in both groups apart from CS, women who had a history of violence had a $33 \%$ increased risk of CS (OR 1.33, 95\% CI 1.021.70) (Table 3$)$. In the total $15.3 \%(n=259)$ of the study population experienced a CS. They were divided between $5.8 \%(n=99)$ women who chose a planned CS and $9.4 \%(n=160)$ who had an emergency CS (exclusively presented in the text). Women with history of emotional abuse had significantly increased risk having CS (OR 1.50, 95\% CI 1.09-2.06) (Table 4). There was also an increased risk of prematurity for women who were experiencing history of violence $6.6 \%(n=43)$ compared to those who were not 4.4. \% $(n=45)$ (Table 5).

Confounding effects of the increased incidence of lower socioeconomic status (cohabiting, employment, economy) and tobacco use on the rate of the two adverse pregnancy outcomes i.e. premature birth and CS showed no potential cause and effect or significant association.

Infant characteristics were similar in the two groups. In addition, there were two intra uterine foetal deaths before gestational week 34 (mothers had not reported experience of violence).

\section{Discussion}

The findings from this study clearly indicate that women who are experiencing DV are at a significantly higher risk of a CS, irrespectively whether the CS is planned or emergency. In line with previous studies, women with a history of violence were also at an increased risk of a premature birth before 37 week of gestation. Tomasdóttir et al. [37] also reported that women with a history of violence were at an increased risk of a CS, however Tomasdóttir did not report on whether the CS was an emergency or planned. BIDENS large cohort study which was conducted in six European countries 
Table 4 Caesarean section in relation to history of violence $(N=1694)$

\begin{tabular}{|c|c|c|c|c|}
\hline \multirow{2}{*}{$\begin{array}{l}\text { Characteristics } \\
\text { Total n (\%) }\end{array}$} & \multirow[t]{2}{*}{ Total } & \multicolumn{2}{|c|}{ Caesarean sectio } & \multirow[t]{4}{*}{$P$} \\
\hline & & No & Yes & \\
\hline & N (\%) & n (\%) & n (\%) & \\
\hline & $1694(100)$ & $1435(84.7)$ & $259(15.3)$ & \\
\hline History of violence ${ }^{1}$ & & & & 0.036 \\
\hline No & $1031(61.1)$ & $889(62.2)$ & $142(55.3)$ & \\
\hline Yes & $656(38.9)$ & $541(37.8)$ & $115(44.7)$ & \\
\hline \multicolumn{5}{|l|}{ Missing $=5$} \\
\hline DV during pregnancy ${ }^{2}$ & & & & 0.924 \\
\hline No & $1660(98.0)$ & $1406(98.1)$ & $254(98.1)$ & \\
\hline Yes & $34(2.0)$ & $29(2.0)$ & $5(1.9)$ & \\
\hline \multicolumn{5}{|l|}{ Missing $=0$} \\
\hline History of emotional abuse ${ }^{3}$ & & & & 0.012 \\
\hline No & $1366(81.4)$ & $1173(82.4)$ & $193(75.7)$ & \\
\hline Yes & $313(18.6)$ & $251(17.6)$ & $62(24.3)$ & \\
\hline \multicolumn{5}{|l|}{ Missing $=15$} \\
\hline History of physical abuse $\mathrm{e}^{3}$ & & & & 0.058 \\
\hline No & $1193(71.2)$ & $1024(72.1)$ & $169(66.3)$ & \\
\hline Yes & $482(28.8)$ & $396(27.9)$ & $86(33.7)$ & \\
\hline \multicolumn{5}{|l|}{ Missing $=19$} \\
\hline History of sexual abuse ${ }^{3}$ & & & & 0.079 \\
\hline No & $1424(84.8)$ & $1217(85.5)$ & $207(81.2)$ & \\
\hline Yes & $255(15.2)$ & $207(14.5)$ & $48(18.8)$ & \\
\hline Missing $=15$ & & & & \\
\hline
\end{tabular}

Pre-specified level of statistical significance $<0.05$, two-tailed

${ }^{1}$ Reported experience of of emotional, physical or sexual abuse in early and/or late pregnancy irrespective severity

${ }^{2}$ Reported experience of of emotional, physical or sexual abuse during pregnancy irrespective severity

${ }^{3}$ Reported experience of emotional, physical or sexual abuse during early second trimester irrespective severity

demonstrated the risk of a planned CS for nonobstetrical reasons in primiparous women who had experienced sexual abuse as an adult was high when compared with women who had not experienced sexual violence [24].

The same study also highlighted an association of an increased risk of preterm birth and DV, validating a recent prospective cohort study by Rishal et al. [38] and a large meta-analysis in 2016 by Hill et al. [21] which also demonstrated a significant increase risk of a preterm birth among women subjected to DV. The consequences of a preterm birth have short- and long-term consequences in infants. Infants born before 37 gestational weeks are vulnerable to major health and developmental risks such as increased risk of respiratory distress and immature brains requiring special care in NICU which in turn result in longer hospitalization [39]. Preterm infants are at higher risk of being readmitted to the hospital and are at an increased risk of death after returning home $[40,41]$. In this study women who reported a history of violence experienced higher levels of depressive symptoms than women who were not experiencing DV. It is established that depression will influence a mother's ability and willingness to bond and take care of her newborn child [42]. A systematic review by Staneva and colleagues reported a significant interface between depression, anxiety and stress, risk factors and preterm birth [43]. Previous research has also revealed that maternal psychosocial stress, and/or fear of childbirth, may have an association with specific complications and increase the women's risk of undergoing a CS [44]. Pregnancy and childbirth can also be psychological memory triggers for women who have experienced childhood sexual abuse [45]. Simkin [46] supports this theory suggesting such complex psychosocial factors, whether remembered or not, have the capacity to play a greater role in perinatal care and outcomes. Finnbogadóttir and Mellgren [47] in a previous study from the same cohort of women revealed that more than one in ten women with a history of emotional abuse had never actually talked to anyone about their experience. Indicating that many women are embarking upon their pregnancy with unprocessed 
Table 5 Infant characteristics and birth outcome $(N=1694)$

\begin{tabular}{|c|c|c|c|c|}
\hline \multirow{3}{*}{$\begin{array}{l}\text { Characteristics } \\
\text { Total n (\%) }\end{array}$} & \multirow{3}{*}{$\begin{array}{c}\text { Total } \\
\text { n (\%) } \\
1687(100)\end{array}$} & \multicolumn{2}{|c|}{ History of violence ${ }^{1}$} & \multirow[t]{3}{*}{$P$} \\
\hline & & No & \multirow{2}{*}{$\begin{array}{c}\text { Yes } \\
\text { n (\%) } \\
656(38.9)\end{array}$} & \\
\hline & & $\begin{array}{c}n(\%) \\
1031(61.1)\end{array}$ & & \\
\hline Gestational week & & & & 0.049 \\
\hline Premature $<37$ weeks & $88(5.2)$ & $45(4.4)$ & $43(6.6)$ & \\
\hline Full term $\geq 37$ weeks & 1599 (94.8) & $986(95.6)$ & $613(93.4)$ & \\
\hline \multicolumn{5}{|l|}{ Missing = 7} \\
\hline Infant biological sex & & & & 0.212 \\
\hline Female & $829(49.3)$ & $494(48.1)$ & $335(51.2)$ & \\
\hline Male & $851(50.7)$ & $533(51.9)$ & $319(48.8)$ & \\
\hline \multicolumn{5}{|l|}{ Missing $=13$} \\
\hline Apgar at 5 min & & & & 0.634 \\
\hline $\begin{array}{l}<7 \\
\geq 7\end{array}$ & $\begin{array}{r}18(1.1) \\
1669(98.9)\end{array}$ & $\begin{array}{c}10(1.0) \\
1021(99.0)\end{array}$ & $\begin{array}{c}8(1.2) \\
648(98.8)\end{array}$ & \\
\hline \multicolumn{5}{|l|}{ Missing $=7$} \\
\hline Infant weight & & & & 0.742 \\
\hline$<2500 \mathrm{~g}$ & $50(3.0)$ & $28(2.7)$ & $22(3.4)$ & \\
\hline $2500-4000$ & $1293(77.3)$ & $790(77.4)$ & $503(77.3)$ & \\
\hline$>4000 \mathrm{~g}$ & $329(19.7)$ & 203 (19.9) & $126(19.4)$ & \\
\hline \multicolumn{5}{|l|}{ Missing = 22} \\
\hline Transferred to NICU & & & & 0.210 \\
\hline Yes & $89(5.9)$ & $49(5.3)$ & $40(6.8)$ & \\
\hline No & $1424(94.1)$ & $879(94.7)$ & $545(93.2)$ & \\
\hline Missing = 181 & & & & \\
\hline
\end{tabular}

Pre-specified level of statistical significance $<0.05$, two-tailed

${ }^{1)}$ Reported experience of emotional, physical or sexual abuse during pregnancy irrespective severity

trauma which can adversely affect the woman's pregnancy and childbirth outcome. However, in this study women with an exclusive history of physical and/or sexual abuse, did not display a significant association with increased risk of CS. This finding however, is in contraindication with some former studies which have shown an increased risk between IPV and CS and physical violence $[48,49]$. Furthermore, a European a large multicountry cohort study in 2016 confirmed that primiparous women who were sexually abused as adults were more likely to have an elective CS for non-obstetrical reasons and multiparous for an emergency CS [24]. To summarize, irrespective of the type of violence a woman experiences a history of violence and ongoing abuse during pregnancy has an overall negative impact on childbirth outcomes. Therefore, it's crucial for midwives to be focussed and observant during the antenatal visits with a pregnant woman. Therefore, it's central that midwives are concentrating and observant in the antenatal period. It is also important that the midwife strives to develop a trusting relationship from the very first encounter and focuses on a woman's holistic health needs. Thereby, providing an opportunity to identify the women who require extra resources and need extra support during such a vulnerable period of their lives.

Previous studies from Sweden testify that on average $2.6 \%$ of women have reported physical abuse by a current or former partner during the year preceding pregnancy, with $1.3 \%$ reporting a history of abuse in the postpartum period [50]. Evidence has shown that a brief training program can improve midwives' ability to recognize the signs of DV, increase their knowledge, preparedness, and confidence to responding sensitively to women [51]. However currently in Sweden it is not routine to ask about DV. For that reason, this study sought to bring forward new knowledge to help midwives and other health care professionals recognize women who are a higher risk of experiencing DV during pregnancy. Pregnancy is an opportune time for early intervention, it is time when women may be open to accessing support. A disclosure which is met with a sensitive, caring and considered response may support and empower women to reach and seek support. Therefore, it is important that a woman-centred approach is secured, this can be achieved by providing care within a midwifery continuity of care model [52]. Providing midwifery continuity of care provides women with care from a known midwife. Continuity of midwifery care provides a greater level of trust and connection between a midwife and the woman thereby increasing the possibility of a disclosure from the woman. However, to provide women centred care, midwives must be supported by their health care organizations to re-organise their current fragmented systems of care. DV education and training is also vital to increase midwives' knowledge and confidence, ongoing training, support and mentoring are vital if midwives are to continue to undertake this sensitive work in a trauma informed way. In addition, DV training programs should be long enough to address the complexities of DV, including addressing attitudes and stereotypes as well as ousting common myths, which surround DV. Continuity of midwifery care through midwifery caseload models is essential, as it provides women with the opportunity to build up a trusting and ongoing relationship with a known midwife. Continuity of midwifery care also offers a greater level of trust and connection between a midwife and the woman and increases the possibility of a disclosure from the woman. However, to provide women centred care, midwives must be supported by their health care organizations to re-organise their current systems of care. Education and training is also vital to increase the midwives' knowledge and confidence, ongoing training, support and mentoring are vital if midwives are to continue to undertake this sensitive work. In addition, DV training program should be long enough 
to address the complexities of DV, including addressing attitudes and stereotypes as well as ousting common myths, which surround DV [51].

There are several strengths to this study the large sample size and the use of a well-defined cohort. This longitudinal study, based on prospective data, also allowed for the robust comparison between those who had history of violence and those who did not. Another strength of the study is the use of validated instruments to evaluate the data $[29,30,33,35,53-55]$.

The authors would also like to acknowledge the limitations to the study, for example, the question How often do you have a drink containing alcohol? should have specified, when pregnant. The results are also limited to those who meet the inclusion criteria and were recruited to participate in the study.

\section{Conclusion}

The results of the study ascertain that a history of violence has a negative impact on a woman's mode of birth and increases the risk of premature birth. Therefore, it is important that midwives strive to develop a relationship which is respectful and built on trust with women during the antenatal period. Early identification of a history of violence and abuse before or during pregnancy could decrease the rates of premature birth and/or CS. The effects of a history of violence including experiencing psychological violence without other forms of violence has serious effects on both maternal and childbirth outcome.

\section{Abbreviations}

ANC: Antenatal Care; BMl: Body Mass Index; CS: Caesarean Section; DV: Domestic Violence; EDS: Edinburgh Depression Scale; EPDS: Edinburgh Postnatal Depression Scale; IPV: Intimate Partner Violence; NorAQ: NorVold Abuse Questionnaire; Q-I: Questionnaire I; Q-II: Questionnaire II; OR: Odds ratios; SOC-13: Sense of Coherence Scale-short form; VAW: Violence Against Women; WHO: World Health Organization

\section{Acknowledgements}

The authors would like to thank all the midwives who carried out the recruitment.

\section{Authors' contributions}

The first author (HF) conceived the study and performed the collection of the data and all authors (HF, KB, LTL) contributed toward data analysis, drafting and critically revising the manuscript and gave final approval of version to be published and agreed to be accountable for all aspects of the work.

\section{Authors' information}

The first author Hafrún Finnbogadóttir, RN, RM, PhD is an Associate Professor at the Faculty of Health and Society, Department of Care Science, Malmö University, Sweden. The second author Kathleen Baird, RM, PhD, is an Associate Professor in the School of Nursing and Midwifery, Griffith University, Transforming Maternity Care Collaborative, Menzies's Health Institute Queensland, Queensland, Australia. The third author Li ThiesLagergren, RM, PhD is a lecturer at the Department of Health Sciences: Child, Family \& Reproductive Health, Health Sciences Centre, Lund University, Sweden.

\section{Funding}

The Swedish Crime Victim Compensation and Support authority contributed with funding for this research (Dnr 09082/2014; Dnr 09097/2015). The role of funding body was in paid time to the analysis, interpreting data and in writing the manuscript. Open access funding provided by Malmö University.

\section{Availability of data and materials}

The datasets used and/or analyzed during the current study are available from the corresponding author on reasonable request.

\section{Ethics approval and consent to participate}

The Current project was accomplished in accordance with the WHO's ethical and safety recommendations for research on DV against women [56]. The main principals to justify this research were fulfilled according to the World Medical Association Declaration of Helsinki [57]. Furthermore, the participants were informed about the law governing the procedures of the Swedish Data Inspection (PUL). At the time of their recruitment, the participants were fully informed about the content of the study and informed written consent was obtained before participation. The women were promised confidentiality and advised that it was entirely up to them if they wished to disclose, to their midwife, that they were living in a violent relationship. Those who were in need of support were guaranteed professional help. Completed questionnaires were collected by the first author, were given a unique code number, and were then kept in a locked safety deposit until they were scanned. Approval was obtained from the Regional Ethical Review Board of Southern Sweden (Dnr: 640/2008)

\section{Consent for publication}

Not applicable.

\section{Competing interests}

The authors declare that they have no competing interests.

\section{Author details}

${ }^{1}$ Faculty of Health and Society, Department of Care Science, Malmö University, Malmö, Sweden. ${ }^{2}$ School of Nursing and Midwifery, Transforming Maternity Care Collaborative, Griffith University, \& Gold Coast University Hospital, Griffith, Australia. ${ }^{3}$ The Department of Health Science: Midwifery research - reproductive, perinatal and sexual health, Health Science Center, Lund University, Lund, Sweden.

Received: 26 September 2019 Accepted: 9 March 2020

Published online: 26 March 2020

\section{References}

1. WHO: Global and regional estimates of violence against women: prevalence and health effects of intimate partner violence and non-partner sexual violence. 2013, (2014, February/1).

2. NCK Nationellt Centrum för Kvinnofrid: Våld och hälsa: en undersökning om kvinnors och mäns våldsutsatthet samt kopplingen till hälsa Violence and health: a study about womens and mens exposure to violence as well as connection to health). 2014, 2014:1:3-94.

3. Finnbogadottir H, Dykes AK, Wann-Hansson C. Prevalence of domestic violence during pregnancy and related risk factors: a cross-sectional study in southern Sweden. BMC Womens Health. 2014;14:63 6874-14-63.

4. Engnes $K$, Liden $E$, Lundgren I. Experiences of being exposed to intimate partner violence during pregnancy. Int J Qual Stud Health Well-Being. 2012; 7. https://doi.org/10.3402/qhw.v7i0.11199 Epub 2012 Mar 15.

5. Edin KE, Dahlgren L, Lalos A, Hogberg U. "keeping up a front": narratives about intimate partner violence, pregnancy, and antenatal care. Violence Against Women. 2010;16(2):189-206.

6. Finnbogadottir H, Dykes AK, Wann-Hansson C. Struggling to survive for the sake of the unborn baby: a grounded theory model of exposure to intimate partner violence during pregnancy. BMC Pregnancy Childbirth. 2014;14(1):293 2393-14-293.

7. Krug EG, Dahlberg LL, Mercy J, Zwi AB, Lozano R. World report on violence and health. Geneva: World Health Organization; 2002.

8. Garcia-Moreno C, Jansen HA, Ellsberg M, Heise L, Watts CH. WHO multicountry study on Women's health and domestic violence against women study team: prevalence of intimate partner violence: findings from the WHO multi-country study on women's health and domestic violence. Lancet. 2006;368(9543):1260-9. 
9. Fisher J, Tran TD, Biggs B, Dang TH, Nguyen TT, Tran T. Intimate partner violence and perinatal common mental disorders among women in rural Vietnam. Int Health. 2013;5(1):29-37.

10. Dobash R, Dobash R. Violence against wives: a case against patriarchy. New York: free press; 1979.

11. Miller E, McCaw B. Intimate Partner Violence. N Engl J Med. 2019;380(9):850-7.

12. Boursnell $M$, Prosser $S$. Increasing identification of domestic violence in emergency departments: a collaborative contribution to increasing the quality of practice of emergency nurses. Contemp Nurse. 2010;35(1):35-46.

13. van der Wath A, van Wyk N, Janse van Rensburg E. Emergency nurses' experiences of caring for survivors of intimate partner violence. J Adv Nurs. 2013;69(10):2242-52

14. World Health Organization (WHO). Responding to intimate partner violence and sexual violence against women: WHO clinical and policy guidelines; 2013. p. 1-68.

15. Australian Institute of Health and Welfare: Family, domestic and sexual violence in Australia 2018.Cat. no. FDV 2.Canberra: AlHW.

16. James $L$, Brody D, Hamilton Z. Risk factors for domestic violence during pregnancy: a meta-analytic review. Violence Vict. 2013;28(3):359-80.

17. FRA European Union agency for fundamental rights. Dignity. Violence against women an EU-wide survey; 2014. p. 1-200

18. Finnbogadóttir H, Dykes AK, Wann-Hansson C. Prevalence and incidence of domestic violence during pregnancy and associated risk factors: a longitudinal cohort study in the south of Sweden. BMC Pregnancy Childbirth. 2016;16:228.

19. Finnbogadóttir $H$, Dykes A. Increasing prevalence and incidence of domestic violence during the pregnancy and one and a half year postpartum, as well as risk factors: -a longitudinal cohort study made in southern Sweden. BMC Pregnancy Childbirth. 2016;16:327.

20. Coker AL, Sanderson M, Dong B. Partner violence during pregnancy and risk of adverse pregnancy outcomes. Paediatr Perinat Epidemiol. 2004:18(4):260-9.

21. Hill A, Pallitto C, McCleary-Sills J, Garcia-Moreno C. A systematic review and meta-analysis of intimate partner violence during pregnancy and selected birth outcomes. Int J Gynecol Obstet. 2016;133(3):269-76.

22. Donovan BM, Spracklen CN, Schweizer ML, Ryckman KK, Saftlas AF. Intimate partner violence during pregnancy and the risk for adverse infant outcomes: a systematic review and meta-analysis. BJOG. 2016;123(8):1289-99.

23. Eberhard-Gran M, Slinning K, Eskild A. Fear during labor: the impact of sexual abuse in adult life. J Psychosom Obstet Gynaecol. 2008;29(4):258-61.

24. Schei B, Lukasse M, Ryding EL, Campbell J, Karro H, Kristjansdottir H, Laanpere M, Schroll AM, Tabor A, Temmerman M, Van Parys AS, Wangel AM, Steingrimsdottir T. A history of abuse and operative delivery - results from a European multi-country cohort study. PLoS One. 2014;9(1):e87579.

25. Provencal N, Binder EB. The effects of early life stress on the epigenome: from the womb to adulthood and even before. Exp Neurol. 2015;268:10-20.

26. Brown SJ, McDonald EA, Krastev AH. Fear of an intimate partner and women's health in early pregnancy: findings from the maternal health study. Birth. 2008:35(4):293-302

27. Janssen PA, Holt VL, Sugg NK, Emanuel I, Critchlow CM, Henderson AD. Intimate partner violence and adverse pregnancy outcomes: a populationbased study. Am J Obstet Gynecol. 2003;188(5):1341-7.

28. Howard LM, Oram S, Galley H, Trevillion K, Feder G. Domestic violence and perinatal mental disorders: a systematic review and meta-analysis. PLoS Med. 2013;10(5):e1001452.

29. Swahnberg IM, Wijma B. The NorVold abuse questionnaire (NorAQ): validation of new measures of emotional, physical, and sexual abuse, and abuse in the health care system among women. Eur J Pub Health. 2003;13(4):361-6.

30. Cox JL, Holden JM, Sagovsky R. Detection of Postnatal Depression. Development of the 10-item Edinburgh postnatal depression scale. $\mathrm{Br} J$ Psychiatry. 1987;150:782-6.

31. Rubertsson C, Borjesson K, Berglund A, Josefsson A, Sydsjo G. The Swedish validation of Edinburgh postnatal depression scale (EPDS) during pregnancy. Nord J Psychiatry. 2011;65(6):414-8.

32. SBU: SBU. Diagnostik och uppföljning av förstämningssyndrom. En systematisk litteraturöversikt (Diagnosis and monitoring of mood disorders. A systematic literature overview). Stockholm: Statens beredning för medicinsk utvärdering (The Swedish Council on Technology Assessment in Helth Care); 2012. SBU-rapport nr 212. ISBN 978-91-85413-52-2. 2012, 212.

33. Antonovsky A. The structure and properties of the sense of coherence scale. Soc Sci Med. 1993;36(6):725-33.

34. Eriksson M, Lindstrom B. Antonovsky's sense of coherence scale and its relation with quality of life: a systematic review. J Epidemiol Community Health. 2007;61(11):938-44.
35. Saunders JB, Aasland OG, Babor TF, de la Fuente JR, Grant M. Development of the alcohol use disorders identification test (AUDIT): WHO collaborative project on early detection of persons with harmful alcohol consumption-II. Addiction. 1993:88(6):791-804.

36. Ekelin M, Crang Svalenius E, Larsson AK, Nyberg P, Marsal K, Dykes AK. Parental expectations, experiences and reactions, sense of coherence and grade of anxiety related to routine ultrasound examination with normal findings during pregnancy. Prenat Diagn. 2009;29(10):952-9.

37. Tomasdottir MO, Kristjansdottir H, Bjornsdottir A, Getz L, Steingrimsdottir T, Olafsdottir OA, Sigurdsson JA. History of violence and subjective health of mother and child. Scand J Prim Health Care. 2016:34(4):394-400.

38. Pun KD, Rishal P, Darj E, Infanti JJ, Shrestha S, Lukasse M, Schei B, ADVANCE Study Group. Domestic violence and perinatal outcomes - a prospective cohort study from Nepal. BMC Public Health. 2019;19(1):671-019-6967-y.

39. Pokras S, Pimenta J, Merinopoulou E, Lambrelli D. Short and long-term costs among women experiencing preterm labour or preterm birth: the German experience. BMC Pregnancy Childbirth. 2018;18(1):284.

40. Shapiro-Mendoza CK, Tomashek KM, Anderson RN, Wingo J. Recent national trends in sudden, unexpected infant deaths: more evidence supporting a change in classification or reporting. Am J Epidemiol. 2006;163(8):762-9.

41. Doctor T, Harnaen E, Seith B, Tan K, Craig S. Risk Factors for Hospital Readmission and Follow Up after NICU Discharge of Infants Born at Extremely Low Gestational Age in Metropolitan Melbourne; 2017. p. 3-28.

42. Alvarez-Segura M, Garcia-Esteve L, Torres A, Plaza A, Imaz ML, HermidaBarros L, San L, Burtchen N. Are women with a history of abuse more vulnerable to perinatal depressive symptoms? A systematic review. Arch Womens Ment Health. 2014;17(5):343-57.

43. Staneva A, Bogossian F, Pritchard M, Wittkowski A. The effects of maternal depression, anxiety, and perceived stress during pregnancy on preterm birth: a systematic review. Women Birth. 2015;28(3):179-93.

44. Johnson RC, Slade P. Obstetric complications and anxiety during pregnancy: is there a relationship? J Psychosom Obstet Gynaecol. 2003;24(1):1-14.

45. Courtois CA, Courtois Riley C. Pregnancy and childbirth as triggers for abuse memories: implications for care. Birth. 1992;19(4):222-3.

46. Simkin P. Early trauma, its potential impact on the childbearing woman, and the role of the midwife. Midwifery Today Int Midwife. 2009;(90):19-21.

47. Finnbogadóttir $\mathrm{H}$, Mellgren $\mathrm{C}$. The degree of suffering among pregnant women with a history of violence, help-seeking, and police reporting. Sex Reprod Healthc. 2017;13:23-8.

48. Cokkinides VE, Coker AL, Sanderson M, Addy C, Bethea L. Physical violence during pregnancy: maternal complications and birth outcomes. Obstet Gynecol. 1999;93(5 Pt 1):661-6.

49. Rachana C, Suraiya K, Hisham A, Abdulaziz A, Hai A. Prevalence and complications of physical violence during pregnancy. Eur J Obstet Gynecol Reprod Biol. 2002;103(1):26-9.

50. Stenson K, Heimer G, Lundh C, Nordstrom ML, Saarinen H, Wenker A. The prevalence of violence investigated in a pregnant population in Sweden. J Psychosom Obstet Gynaecol. 2001;22(4):189-97.

51. Baird KM, Saito AS, Eustace J, Creedy DK. Effectiveness of training to promote routine enquiry for domestic violence by midwives and nurses: a pre-post evaluation study. Women Birth. 2018;31(4):285-91.

52. Sandall J, Soltani H, Gates S, Shennan A, Devane D. Midwife-led continuity models versus other models of care for childbearing women. Cochrane Database Syst Rev. 2016;4:CD004667.

53. Wickberg B, Hwang CP. The Edinburgh postnatal depression scale: validation on a Swedish community sample. Acta Psychiatr Scand. 1996;94(3):181-4.

54. Antonovsky A. Unraveling the mystery of health: how people manage stress and stay well. 1st ed. San Francisco: Jossey-Bass; 1991.

55. McFarlane J, Parker B, Soeken K, Bullock L. Abuse assessment screen. J Med Assoc. 1992;267:3176-8.

56. World Health Organization: Putting women first: Ethical and safety recommendations for research on domestic violence against women. 2001, WHO/FCH/GWH/01.1 Geneva, Switzerland.:.

57. WMA General Assembly: Fortaleza, Brazil 2013: World Medical Association Declaration of Helsinki. Ethical Principles for Medical Research Involving Human Subjects. $(2013,10 / 30)$

\section{Publisher's Note}

Springer Nature remains neutral with regard to jurisdictional claims in published maps and institutional affiliations. 